\title{
Characterization of Reclaimed Asphalt Pavement and Optimization in Polymer Modified Asphalt Blends: A Review
}

\author{
Tiza Michael ${ }^{*_{1}}$, Chika Duweni ${ }^{2}$, Onyebuchi Mogbo ${ }^{3}$, Terlumun Sesugh ${ }^{4}{\text { Asawa } \text { Jacob }^{5}}$ \\ ${ }^{1}$ Civil Engineer, China Civil Engineering Construction Corporation (CCECC)Nigeria Limited. \\ ${ }^{2}$ Associate Lecturer, Civil Engineering Department, University of Ibadan, Nigeria. \\ ${ }^{3}$ Senior Lecturer, Civil Engineering Department, Nile University of Nigeria, Abuja. \\ ${ }^{4}$ Lecturer, Civil Engineering Department, Air force Institute of Technology Kaduna, Nigeria. \\ ${ }^{5}$ Post Graduate Scholar, Civil Engineering Department University of Nigeria Nsukka, Enugu State, Nigeria.
}

\section{Keywords}

Characterization,

Reclaimed

Asphalt

Pavement (RAP),

Optimization

Polymer Modified Asphalt.

\begin{abstract}
This study reviews relevant literature on the characterization of reclaimed asphalt pavement (RAP) and its interaction with polymer modified asphalt(PMA). The study on fatigue cracking indicates that several indexes of binder performance usually decreased the tolerance to cracking of the Polymer Modified Asphalt (PMA). In another perspective, RAP binding rigidity affects the PMA binder tolerance to fatigue. The greater the rigidity of the RAP binder, the more fatigue strength the binders would provide. In addition, several researchers have demonstrated that the quality of RAP binder decreased the elastomeric response worth. It was generally found that the RAP binder effect on the PMA binder is similar to the unmodified binder effect. The resistance to rutting in the PMA binder improves and at the same time, fatigue cracking and thermal cracking are adequately minimized. Moreover, several researchers have shown that the inclusion of a RAP lowers elastomeric efficiency. In summary, RAP binding stiffness and gradation are essential features for PMAmix designs. The review further illustrates that during the process of RAP binder characterization, the mortar testing process without the use of binder extraction is more effective than the conventional method. Also, the best measure for the evaluation of the fatigue cracking efficiency of RAP containing PMA blends does not seem to have gained any consensus among researchers as several researchers seem to have varying conclusions. Literature on Life Cycle Analysis of RAP has also been reviewed and presented.
\end{abstract}

\subsection{Introduction}

An assessment of the literature was undertaken to obtain and study the information available about RAP features, approaches, and RAP effects on the performance of PMA. To identify essential RAP properties affecting PMA mixture efficiency and promising methods for RAP characterization and to conduct the assessment of PMA mixtures containing RAP.

Reclaimed Asphalt pavement(RAP) consists of asphalt and an aggregate developed by damaged roads. As RAP contains old and more brittle asphalted binders than virgin binders, an increase in RAP will increase its susceptibility to cracking. A review of research of inservice pavement and different climates found that pavements with a RAP of $30 \%$ had more cracking paths than those with virgin materials [59]. However, a more recent study has demonstrated that RAP does not decrease the cracking tendencies and overall performance of pavements.

2.0 Characterization Techniques and Characteristics of Recycled Asphalt Pavement (RAP)

Reclaimed Asphalt Pavement (RAP) is a material obtained by dredging pavement with the Cold Milling Method. The use of the reclaimed asphalt pavement is improved year after year. With the use of RAP which reduces the degradation of natural resources, it is important to study this material to allow for optimum use of RAP [12].

Asphaltic content, RAP gradation, and properties of RAP aggregates, including bulk-specific gravity and Superpave aggregate properties, are essential for asphalt mixtures. If blending charts are necessary for a suitable virgin grade binder for higher RAP material, the continuous grade of a RAP binder is required [12]. Asphalt pavement recycling provides a reuse mechanism for materials that optimizes the harm to the environment. RAP is a beneficial alternative to virgin materials as it reduces the need of using virgin aggregates.

The asphalt contents of the RAP are determined by two main methods called the ignition method (AASHTOT 308) and solvent extraction method (AASHTO $\mathrm{T}$ 164). The method of ignition has been the most popular but involves corrective factors based on experience, calculation, and or assumption. The process of extraction involves the application of solvents, which is a concern. In general, the asphalt content of RAP is between $4 \%$ and $6 \%$. This study has demonstrated that asphalt content increases when the RAP particles are finer [10].

The general physical properties of RAP are as presented in the tables below.

2.0 Characterization Techniques and Characterıstics of Recycled Asphalt Pavement (RAP)

Asphalt Pavement Reclaimed (RAP) is a material obtained by dredging pavement with the Cold Milling Method. The use of the reclaimed asphalt pavement is improved year after year. With the use of RAP year after year, even in the damaging of natural resources, the study must be done in respect of the content of materials used in RAP to allow optimum use of RAP [12].

Asphaltic content, RAP gradation, and properties of RAP aggregates, including bulk-specific gravity and Superpave aggregate consensus properties, are essential for asphalt mixtures. If blending charts are necessary for a suitable virgin grade binder for higher RAP material, the continuous grade of a RAP binder is required [12]. Asphalt 
pavement recycling provides a reuse mechanism for materials that optimizes the harm to the environment. RAP is a beneficial alternative to virgin materials as it reduces the need of using virgin aggregates.

The asphalt contents of the RAP are determined by two main methods called the ignition method (AASHTOT 308) and solvent extraction method (AASHTO $T$ 164). At the same time, RAP aggregates are recovered. The method of ignition has been the most popular but involves corrective factors based on experience calculated or assumed. The process of extraction involves the application of solvents, which is a concern. In general, the asphalt content of RAP is between $4 \%$ and $6 \%$. The study has demonstrated that asphalt content increases when the RAP particles are finer [10]. The general physical properties of RAP are as presented in the tables below.

Table 1. Specific gravity test results of RAP, RAP aggregate and fresh aggregate [52]

\begin{tabular}{|c|c|c|c|c|c|c|c|c|c|}
\hline \multirow{3}{*}{ Properties } & \multicolumn{8}{|c|}{ Aggregate Particle Size } & \\
\hline & \multicolumn{2}{|c|}{$10-20 \mathrm{~mm}$} & \multicolumn{3}{|c|}{$5-10 \mathrm{~mm}$} & \multicolumn{4}{|c|}{$<5 \mathrm{~mm}$} \\
\hline & RAP & RAP & FA & RAP & RAP & FA & RAP & RAP & FA \\
\hline Bulk SG & 2.060 & 2.243 & 2.937 & 2.109 & 2.192 & 2.762 & 1.937 & 1.968 & 2.565 \\
\hline SSD SG & 2.090 & 2.277 & 3.014 & 2.133 & 2.227 & 2.841 & 1.976 & 2.016 & 2.688 \\
\hline Apparent SG & 2.122 & 2.322 & 3.183 & 2.170 & 2.272 & 3.000 & 2.016 & 2.068 & 2.926 \\
\hline Absorption (\%) & 1.416 & 1.506 & 2.632 & 1.117 & 1.611 & 2.878 & 2.041 & 2.459 & 4.822 \\
\hline
\end{tabular}

Table 2. Unit weight test results of RAP, RAP aggregate, modified gradation RAP, and fresh Aggregates [52]

\begin{tabular}{|c|c|c|c|c|}
\hline Property (gr/cm3) & RAP & Modified Gradation RAP & RAP Aggregate & Fresh Aggregate \\
\hline Loose unit weight & 1.418 & NA & 1.713 & NA \\
\hline Dense unit weight by pierced using stick & 1.534 & NA & 1.854 & NA \\
\hline Dense unit weight by shake & 1.568 & NA & 1.876 & NA \\
\hline Dense unit weight using standard Proctor & 1.640 & 1.701 & NA & 2.110 \\
\hline Dense unit weight using standard Proctor & 1.677 & 1.770 & 2.010 & 2.261 \\
\hline
\end{tabular}

According to [32], findings of a collaborative study performed by Nevada-Reno University (UNR) and the National Center for Asphalt Technology (NCAT) suggests that the best approach for recovering a specific gravity of aggregate of the RAP for high RAP content compositions is the technique of extracting the solvent which is called the solvent extraction method then the coarse and fine parts of the recovered aggregate are tested respectively using AASHTO T 85 and T 84

The ignition technique could also be used to recover the RAP aggregate for the determination of the specific gravity of the RAP, excluding certain aggregate types which when subjected to temperature extremes, change specific gravity. [59] found that the results of bulk specific gravity (Gsb), are likely to produce minor errors with both methods of recovering RAP aggregates.

According to [42], a recent Florida Department of Transportation (FDOT)-funded University of Florida study assessed cracking performance of PMA mixtures and RAP for a mix of two origins of RAP and three contents of RAP using the Superpave Indirect Tensile Test(IDT). RAP gradation has been shown to influence the propagation of the RAP binder via the Polymer-modified asphalt (PMA) variations. Mixtures of raw RAP demonstrated greater cracking resistance than with fine RAPs on all three RAP contents $(20 \%, 30 \%$, and $40 \%)$, but the coarse RAP was far more rigid than with the fine RAP. RAP binder characteristics comprise primarily a continuous grade established by Superpave performance grade (PG) binder test, penetration, and viscosity determined by conventional consistency tests. For 33 RAP samples collected in Indiana and over 200 virgin asphalt binder samples covering three PG 22 grades and three PG- 28 grade samples [10] assessed for real low-temperature grades and high-temperature grade.

It was estimated that the highest volume of RAP (binder substitution) was $22.7 \%$ for the PG-22 binder as well as $38.1 \%$ for the PG-28 binder. The results of a concurrent mix research method performed at the North Central Superpave Center, which measured stiffness and the cracking ability of mixtures with a RAP of up to 40 percent, and was also confirmed by [10].

Indiana Transportation Department (INDOT) has therefore modified the minimum specification to allow a 25 percent binding replacement without modifying the virgin binding grade and 40 percent binder substitution with one grade at the low and high temperatures. To obtain loss of relaxation or variations in asphalt binding brittleness due to increased degree of asphalt binders' replacement or accelerated aging, a Delta Tc parameter has now been employed [46].

The Delta Tc parameter is described as the variation between the low continuous stiffness temperatures and the $\mathrm{m}$ value as calculated by the bending beam rheometer (BBR) of the Superpave.

In a study investigating the relationship between both the asphalt mix properties and block cracking in pavements in airports, the original parameter was introduced by [6] to evaluate the loss of ductility and relaxation of aged asphalt binder. For the identification of binders prone to unloaded cracking, a minimum of Delta Tc of $-5^{\circ} \mathrm{C}$ (Delta Tc Criteria Minimum) is being used. Asphalt binders have been shown to crack more often as their Delta Tc was negative and less than the limit.

Current research studies have shown that the Delta Tc minimum criteria for assessing the effect of REOBs (recycled engine oil bottoms) on the efficiency of asphalt binders [34,46] as well as on the efficiency of RAP blended with rejuvenators [64]. The findings of the most recent studies have shown the possible use of the DeltaTc minimum criterion. The majority of the studies have followed the existing standard to recover RAP binder by solvent extraction and recovery method, especially for high RAP content mixtures, and then determine the characteristics of the RAP binder. The extraction and recovery of solvents have, however, been criticized for the long-term alteration of binder properties because of the residual solvent after regeneration, high-temperature binder aging, and intensity of work [46].

Furthermore, there are concerns about the environmental and health impacts of the process. Methods have been developed to estimate the properties of RAP binder using mortar or mix tests for the characterization of the non-solvent-based binder. Methods to determine binder characteristics from tests include back-calculation of samples by gyratory compaction and study of thin beam samples taken from gyrated samples [11, 22] and of thin beam samples [78]. [18] launched the back-calculation process after improving the Hirsch model in an attempt to estimate HMA's dynamic modulus by using the shear modulus of the asphaltic binder including volumetric characteristics of the blend. 
Since the process involves a mixing configuration for gyrate specimens, which may be more labor-intensive than the extraction of solvents and reconstruction, to achieve sensible stiffness values from the calculated mixing modulus. It is worth noting that during the RAP characterization stage a mix design for RAP may not be availed.

2.1 RAP Binder Effect on the Polymer-Modified Asphalt (PMA) Binder Properties.

RAP binder's aging and stiffness can affect PMA mixtures' performance. There is also concern that RAP binder can dilute and reduce the efficiency of PMA binders. This section will also address the effect of a RAP binder on the viscosity of a PMA binder and other properties associated with various distresses, including fatigue cracking, thermal crack, and rutting.

\subsection{Fatıgue Cracking Binder Properties}

So many researchers' studies have shown that the inclusion of RAP binder has a negative impact on PMA binder characteristics, especially regarding the resistance of fatigue cracking [30,39 42,50].

All such findings were based on multiple connecting studies, including Binder Fracture Energy (BFE) tests, Linear Amplitude Sweep, and Double Edge notched tension Test results. The addition of a RAP binder was found to increase in $G^{*}$ sinć indicating a less fatigue resistance to cracking; [30, 42]. To assess fatigue crack resistance, PG binder $G^{*} \sin T$ measured with the DSR test at intermediate service temperature was used. To achieve good fatigue resistance, the asphalt binder must be elastic, but not too rigid. $G^{*} \sin S$ must be less than $5,000 \mathrm{kPa}$, as per Superpave specifications. Also, when higher PG grades RAP binders have been used, a greater impact of RAP binder on $\mathrm{G}^{\star} \sin \mathrm{T}$ is observed. [39] used a more rigid RAP binder obtained from the modified asphalt concrete of the 8 years old polymers. The RAP binder was mixed in differing proportions with virgin PMA (PG 70-22) binder ( 0 percent, 20 percent, 40 percent, and 60 percent). According to [30] the $G^{*} \sin 5$ parameter, the overall Superpave requirement was above $5000 \mathrm{kPa}$ at $25^{\circ} \mathrm{C}$ for all RAP binder PMA binders and the overall Superpave requirements.

[51] recently found that recovered RAP binder has negatively impacted PMA binder fatigue life by the intermediate $\left(25^{\circ} \mathrm{C}\right)$ LAS test. PMA (PG 76-xx) binder has been combined with RAP binder (PG 88-xx) in four different contents ( 0 percent, 15 percent, 25 percent, and 40 percent). The parameter Nf (number of failure cycles) was computed with LAS test results which showed the cracking efficiency of the binder fatigue. The growing amount of RAP binder has been found to minimize Nf of the PMA binder.

Table 3. DSR test results related to fatigue cracking in previous studies. [12].

\begin{tabular}{|c|c|c|c|c|c|}
\hline Authors & \multicolumn{2}{|c|}{ [39] } & {$[30]$} & \multicolumn{2}{|c|}{$[42]$} \\
\hline PMA binder grade & \multicolumn{2}{|c|}{ PG 70-22 } & PG 76-22 & \multicolumn{2}{|c|}{ PG $76-22$} \\
\hline RAP binder grade & \multicolumn{2}{|c|}{ Unknown $^{1)}$} & PG 82-16 & PG 100-12 & PG 94-24 \\
\hline Testing temperature & $25^{\circ} \mathrm{C}$ & $28^{\circ} \mathrm{C}$ & $25^{\circ} \mathrm{C}$ & $26.5^{\circ} \mathrm{C}$ & $26.5^{\circ} \mathrm{C}$ \\
\hline $0 \% 2)$ & - & 1.036 & 3.500 & 1.545 & 1.545 \\
\hline $15 \%$ & - & - & 3.900 & - & - \\
\hline $20 \%$ & 5.229 & 3.716 & - & 2.690 & 2.305 \\
\hline $25 \%$ & - & - & 4.000 & - & - \\
\hline $30 \%$ & - & - & - & 2.860 & 2.240 \\
\hline $35 \%$ & - & - & 4.100 & - & - \\
\hline $40 \%$ & 6.911 & 6.911 & - & 4.025 & 2.925 \\
\hline $60 \%$ & 8.889 & 7.064 & - & - & - \\
\hline $100 \%$ & - & - & $8.000^{3)}$ & - & - \\
\hline
\end{tabular}

[42] found that RAP binder addition reduced PMA binding energy fracture (FED). In general, many binder performance indexes reveal that using the recovered RAP binder generally decreases the PMA binding resistance to fatigue cracking. RAP binder stiffness affected the fatigue resistance of the PMA binder. The higher the RAP binder's stiffness, the more effective the blended binder's fatigue resistance is. Moreover, several scientists have shown that the addition of a RAP binder decreases elastomeric interaction effectiveness.

\subsection{RAP Binders and Virgin Asphalt Binders Blending}

Significant amounts of reclaimed asphalt pavement (RAP) are generated, with the aging of the asphalt pavement. In the past few years, the amount of Virgin Bitumen and Aggregate Materials has risen significantly and RAP needs to be recycled more effectively to reduce the cost of mixtures and the negative environmental impacts.

Certain agencies are only permitting 10-25percentage RAP in recycled asphalt, which leads substantially to a low rate of RAP use and directly decreases recycled asphalt material's economic advantage. The blending of virgin and RAP binders in Recycled Asphalt Materials(RAM) is assumed by many highway departments, but this presumption does not exist for RAM with high RAP content.

Till now, various studies have investigated the influence on RAM of high RAPs [45].[29] assessed the cracking resistance of RAM, which revealed that the addition of RAP normally improves the mixture's stiffness and tensile strength indirectly. In comparison, the mixture characteristics differ considerably by 30 percent compared to $10 \%$ and $20 \%$ for RAP content, [29].
Studies found that RAM is more vulnerable to different cracking modes (such as thermal, fatigue, and reflective cracking) with increased RAP content, but is likely to experience lower crack resistance and damage concerning moisture. The major explanation is that the RAP binder is stiffer unlike virgin bitumen, and the varying viscosities of its formulations contribute to a poor blending of RAP binders and virgin bitumen at the blending process.

Since the virgin and RAP binders do not mix entirely, the final product comprises comparatively poor regions; therefore, RAM displays a lowtemperature decreased water stability, and low fatigue crack resistance $[4,21]$.

Thus the blending degree of virgin and RAP binders must be measured to improve the RAM output and increase its RAP content. Several experiments investigated the combination of pure bitumen for virgin and RAP binders, which were valuable for testing on the mixing stage of RAP and virgin binders $[25,73,74]$.

For instance, the mixture of virgin and RAP binders on a recycled binder layer was quantitatively analyzed by [14] the degree of blending was derived of RAM employing spectroscopy, gelpermeation chromatography (GPC) and Fourier transform infrared (FTIR) [13].The study of the blending condition of virgin and RAP binder in RAM appears difficult in contrast to pure bitumen because of the effects of aggregates, fibers, and other materials; thus, the use of tracer is a feasible method to differentiate virgin bitumen from the RAP binder and to investigate the extent of mixing of RAP and virgin binders in RAM. [26] used computed X-ray tomography to examine 
qualitatively the blending condition of metal powder virgin bitumen in the simulated asphalt mix and found only a partial mixture of virgin and RAP binders.

In previous research, Carboxyl-terminated butadiene acrylonitrile (CTBN), was used to map the movements of virgin bitumen [65], and FTIR was used to qualitatively investigate the degree of mixing of virgin and RAP binders in RAM.

The findings revealed, however, that the mixing conditions of virgin binders and RAP bonding systems are based on the role of RAP, and are not hierarchically uniform across the three sample surfaces. It is also an essential quantitative analysis to evaluate the suitable virgin bitumen quality and RAM output mixing parameters. As FTIR can be used to identify alteration in chemical function groups [56,63,77], the RAM mixing degree of virgin binders and RAP binders, high percentage RAP, can be mixed between FTIR and CTBN directly and quantitatively.

One of the major problems with RAP mix designs is how well the RAP binder and virgin binder mix. The state-of-the-art method is used to assess whether the binder rating is modified based on the RAP material used in the blend (AASHTO M 323).

The three-stage method suggests that the RAP and the virgin binders are fully combined. A blending diagram study is suggested to assess the right virgin binder grade for RAP material greater than 25 percent.

Table 4: Binder RAP Mixtures Selection Guidelines (AASHTO M 323)

\section{RAP PERCENTAGE}

Less than $15 \%$

Between $15 \%$ to $25 \%$

Greater than $25 \%$

\section{RECOMMENDED VIRGIN BINDING GRADE}

No Change in binder selection

Select virgin binder one grade softer than the norma

Follow blending chart's recommendations.
Several studies to assess the degree of blending were done. The stiffness of $\left|G^{*}\right|$ calculated on reclaimed binders was used for one approach. [29] analyzed how much virgin binder has been incorporated into the RAP binder by a process called staged extraction.

A mixture of 20 percent fine RAP (sieve no.4) with coarse virgin aggregates that was retained of the sieve no.4 and a virgin binder PG 64-22 was produced within three minutes at a mixing temperature of $190^{\circ} \mathrm{C}$.

Sequentially, trichloroethylene (TCE) was used for four layers of asphalt from the fine RAP mixture. The findings revealed that asphalt layers obtained from the RAP particles had a thickness of 2.0, 1.1, 1.8 and 1.6 microns, from outside to inside. The binder in both inner layers was identical to the RAP binder, which revealed no mixing. In both outer strata, the virgin binder seemed to combine with the RAP binder only when the binders were lower than the RAP binder's stiffness. The experimental technique for calculating the degree of blending was developed by [47]. To confirm the definition, two virgin binders (PG 70-28 and PG 58-28) were selected: one mixture design(JMF), one RAP source with two contents (25 percent, and one aggregate weight with 35 percent).

The blend degree was found to be $70 \%$ for the virgin binding PG 70-28 with $25 \%$ RAP, and $96 \%$ for the virgin binder PG 58-28 with 35\% RAP. In all the studies described above the processes for the processing of the mixtures were fine RAP (- No.4 or â No.8 sizes) and coarse virgin aggregates (+ No.4 sieve size). The degree of mixing into actual mixtures is not quantified in this method.

[20] had followed up a different approach by comparing calculated and expected Superpave dynamic modulus of 45 percent RAP structural mixture fractionated by $1 / 4$ inch Superpave Structural mixture. The coarse part was listed as PG 82-16 and the fine part was PG 82-10. A PG 52-28 binder was used as the virgin binder, the designated recycling agent (RA) 800. Driven by a variety of temperatures and frequencies determined by the dynamic modulus, $\left|E^{\star}\right|$ with the asphalt mixture performance test (AMPT).

The binder was separated and reclaimed from the mix, which fully blended the virgin binder and RAP binder. The recovered binders were examined with the frequency sweep to obtain the binder shear modulus ${ }^{*}$ in a Dynamic Shear Rheometer (DSR). The dynamic modulus, $\left|E^{\star}\right|$, of virtual specimens with totally blended binders was measured using the Hirsch model using inputs of the binder shear modulus, voids in mineral aggregate (VMA), and voids filled with asphalt (VFA) from the specimens that were compacted. The $\left|E^{\star}\right|$ which was predicted was plotted with measured $\left|E^{\star}\right|$. The findings showed predicted and measured values dropped in the same manner, suggesting that in test failures the Hirsch model tended to forecast the measured values.

[42] recently tested the properties of Polymer-Modified Asphalt PMA mixtures with high RAP content in a recent Florida Department of Transportation research. Two different types of RAP sources were chosen: one fine RAP with standard Florida binder stiffness (PG 94-24) and a coarse RAP with an exceptionally stiff binder (graded as PG 10012)

RAP gradation was shown to dominate mix properties as the study had shown. Even though the rough RAP was considerably stiffer than the fine RAP, the mixture had a less resilient modulus than the fine RAP, which suggested that the mixtures were not completely blending between Virgin and RAP, rather than the RAP binder being near to the RAP aggregate.

In comparison, coarse RAP generated more energy than fine RAP. The more thinly mixed mix with coarse RAP, which is mostly a virgin aggregate and virgin binder, does no longer generally have an advantageous mixing strength.

All in all, the literature has demonstrated that absolute mixing will take place where the soft-virgin binder is used in asphalt mixtures using a slightly aged RAP. The RAP binder and virgin binder have however not necessarily been thoroughly blended in asphalt mixtures. In partial blending, the RAP binding appeared to remain close to the RAP aggregates, resulting in an inconsistent asphalt blending of the RAP binder.

\subsection{Lıfe Cycle Analysıs of RAP}

Study of Reclaimed Asphalt Pavement (RAP) Life Cycle Costs under Future Climatic Change. Reclaimed asphalt is a byproduct of the rehabilitation of the asphalt pavement and is used in hot mixed asphalt(HMA) as an alternative material. The lower environmental and economic effect of the recycled asphalt pavement (RAP) with RA was noticed as compared to HMA $[8,27,44,65]$

The use of RA is generally motivated by economic/environmental gains of material processing and transport [20]. From a life cycle cost analysis (LCCA) point of view, such benefits are just a part of the cumulative effects on the economy and environment. The LCCA, in this report, is concerned with a systematic methodology for the quantification and comparison of cash flow over an enclosure life cycle. The cash flow may occur not only during the manufacture and transport of the pavement materials but also in the building, maintenance, usage, and end-of-life recycling stages of the pavement.

The economic advantages of using RA in base paving and subbase layers were examined by [33]. An LCCA was carried out, taking into 
account the agency and expense of users. The performance of lifespan the life cycle was expressed by the roughness of the pavement and used further to estimate the quality of the pavement. In contrast with [44] carried out a detailed LCCA analysis contrasting the economic benefits and disadvantages of reclaimed on-site pavements and conventional pavement. The LCCA covered material procurement, manufacture, construction, repair, rehabilitation, transport, cost of work areas, utilization and recycling phases of end-of-life. In this review, the roughness of the road is discussed. It was found that both agency and user expenses could be minimized utilizing RAP. Although the roughness of many LCCA analyses has been widely considered, the advantages/disadvantages of using Recycled asphalt often depend on the performance of rutting and cracking [58]. A detailed performance It has been concluded that high RA pavements result in lower life cycle costs as supported by [8]. Furthermore, dynamic modulus testing was recommended in order to maximize the prediction and precision of the LCCA efficiency of the life cycle. The efficiency of the RAP LCCA is critical because it can affect the reliability, rider efficiency, particularly because the cost of the agency (e.g. maintenance expense) and cost of the user (such as fuel consumption) can be calculated $[53,57]$.

Although incoherence in the laboratory performance assessment of RA remains, it is widely accepted that RA could increase the rutting resistance of pavement surfaces, but it decreases resistance to thermal cracking as the RA could enhance mixtures' brittleness $[4,48]$.

Furthermore, traditional mix and LCCA design typically take on a specific climate. The life cycle efficiency and costs as a climatesensitive infrastructure may be affected by potential varied climate patterns $[40,54]$. In addition, in different climactic zones the value of longevity may be different.

In cooler climates, for instance, rutting is not critical for asphalted paving, but thermal cracking can develop. Rutting can be critical, but not thermal cracking, in hot climates. Therefore, it is important that the efficiency of the life cycle and the expense of the pavements be considered for local climates and material responses. While the longevity and economic advantages of RAP will change in future climates, they are regarded as a more financial alternative to virgin HMA.

Therefore, in order to determine whether it is economic for road agencies to use RA in the future pavements, it is necessary for them to evaluate and compare life-cycle costs of pavements with recycled asphalts and those without recycled asphalts in anticipated future climates.

\subsection{The Effect of Heating Temperature on the Recycled Asphal Pavement}

The increased demand for asphalt rehabilitation contributes to the production and recycling of increasing amounts of reclaimed asphalt pavements (RAPs). As a result, since RAP requires useful asphalt binders and aggregates, the Virgin Binder may be replaced, which is a huge environmental and economic gain for new asphalt pavement construction and rehabilitation of asphalt pavement. [39]. The techniques of recycling are a hot subject of study with interest from a number of researchers across the globe.

The recycling approaches can be categorized as hot recycling (HR) and cold recycling (CR) [63], depending on recycling processes and mixing temperature. Although the environmental benefits of CR [35] are higher, a large spectrum of applications is given for HR recycling technologies, due to their enhanced performance [72].

Temperature is considered as a key factor in compacting recycled HMA, as is the case with the fresh Hot Mix Asphalt (HMA), and poorly compacted mixtures can cause extreme rutting, resistance to fatigue, poor durability and excessive moisture damage [28]. Enhanced heating in a drum mixing plant the temperature of the RAP is normally done to raise the temperature. Nevertheless, such a rise in temperature does not necessarily mean the recycled mixture is more compact. Many studies have demonstrated that the aged binder in
HMA pavements, it is concluded that the adoption of RAP will minimize the costs of life spans by about 20 percent.

appraisal of the life cycle is therefore required to evaluate Maintenance and corresponding cost elements of the life cycle.

For instance, [19] carried out a mechanistic-empirical life cycle simulation and an LCCA of RAP and conventional pavements [19]. This research considered many measures of life cycle. This research considered many measures of life cycle the expenses for raw materials, supplies, labor, road construction and lane closure were taken into account in the LCCA.

RAP and virgin binder is blended from 0\% (black rock) to 100\% (full blending) [29].

In the zero blending, the binder RAP is like a rock, so it does not cover other virgin aggregates. Once the binder is completely blended, it would have identical properties to those of the binder around the virgin aggregate. The mixed temperature is of considerable significance in increasing the mixing ratio, as both binders can be melted with the hot virgin aggregates and hot virgin binder [14]; at the same time, the rejuvenator penetration speeds up the diffusion between the virgin and the aged asphalted binder [56].

The heating temperature of RAP would almost certainly affect the degree to which the two binders are blended. The higher the temperature of the heating system, the more effective age-old binder will cause the greater the degree of blending. The effect of the raising of the RAP temperature is however two ways. On the first side, a more active aged binder can integrate an aged binder into the mixed binder, which results in an increase in viscosity.

From the other end, due to the increase in temperature the viscosity of the mixed binder would be reduced. Consequently, the effect on the compactability of the recycled HMA of the RAP heating temperature is very dynamic, which is the two aforementioned successful effects.

\subsection{Binder Properties Related to Thermal Cracking}

Initial studies based on BBR test results have shown that PMAs with reclaimed RAP binders usually exhibited decreased resistance against cracking at low temperatures compared to PMA binder control $[42,50,53]$.

The BBR test introduces parameters for calculating the binding resistance to low-temperature cracking: $\mathrm{m}$-value and $\mathrm{S}$ (creep stiffness). [50] noted a rise in the SBS PMA binder stiffness (PG 76-xx), with a decrease in the m-value of both RAP origins. These findings showed the low-temperature efficiency of PMA binders was negatively impacted by the recovered RAP binder.

[42] also identified an improvement in BBR creeping stiffness of PG 7622 PMA binder, and lowered $m$ value of recovered RA PG Binding (PG 100-12 and PG 94-24). It becomes essential to remember, however, that all mixed binders satisfy the specification of the Superpave.

In general, RAP binder effects for PMA binder were similar to unmodified binder effects. The RAP binder in PMA binders improved, increasing the rutting resistance and decreasing the thermal cracking and fatigue cracking resistance. Moreover, some researchers found that the addition of a RAP binder decreased elastomeric behavior efficiency. Multiple stress creep and recovery However, findings of the multiple stress creep and recovery (MSCR) test revealed that elastomeric behavior was maintained in the mixed binder with a high proportion of RAP stiffness binders (40 percent).

\section{Conclusion}

In general, it has been observed that the effect of RAP binder on PMA binder is close to the unmodified binder effect. The amount of rutting resistance in the PMA binder had increased, and fatigue cracking and thermal cracking resistance were reduced. Also, several researchers have found that the addition of a RAP binder decreases elastomeric behavior performance. Results from this MSCR test show that 
elastomeric actions persisted in the mixed binder with a high proportion of RAP binder with high rigidity. Also, the addition of a stiffer RAP binder has been seen to have a stronger influence on the PMA binding properties. It is therefore important to define the RAP binder so that its effect on the PMA binder is better estimated. On the other hand, it was generally found that the RAP binder effect on the PMA binder is similar to the unmodified binder effect. The resistance to rutting in the PMA binder had improved and fatigue cracking and thermal cracking were minimized. Moreover, several researchers found that the inclusion of a RAP binder lowers elastomer efficiency.

In summary, both RAP and RAP stiffness were seen to be essential features in the appropriate RAP-containing PMA mix designs. The mortar testing procedure without the need for binder extraction seemed more convenient for RAP binder characterization than the traditional method. Also, there is no consensus on the best test to determine the efficiency of fatigue cracking in PMA RAP mixtures.

\section{Declaration of Conflict of Interests}

The authors declare that there is no conflict of interest. They have no known competing financial interests or personal relationships that could have appeared to influence the work reported in this paper.

\section{REFERENCES}

[1.] AASHTO Standard Specification for Superpave Volumetric Mix Design, AASHTO M323, 2017.

[2.] Al-Qadi, I. L., Carpenter, S. H., Roberts, G., Ozer, H., Aurangzeb, Q., Elseifi, M., and Trepanier, J, Determination of Usable Residual Asphalt Binder in RAP." Illinois Center for Transportation (ICT). Final Report of Federal Highway Administration, FHWA-ICT 09031. . (2009).

[3.] Al-Qadi, I.L.; Aurangzeb, Q.; Carpenter, S.H.; Pine, W.J.; Trepanier, J. Impact of High RAP Contents on Structural and Performance Properties of Asphalt Mixtures. FHWA-ICT-12-002. 2007.

[4.] Al-Qadi, I.L.; Elseifi, M.; Carpenter, S.H. Reclaimed Asphal Pavement-A Literature Review; Report: FHWA-ICT-07-001; FHWA:Washington, DC, USA, 2007.

[5.] American Association of State Highway and Transportation Officials (AASHTO). Mechanistic-Empirical Pavement Design Guide (MEPDG), version 1.1; National Cooperative Highway Research Program: Washington, DC, USA, 2009.

[6.] Anderson, R. M., King, G. N., Hanson, D. I., and Blankenship, P. B. Evaluation of the Relationship Between Asphalt Binder Properties and Non-Load Related Cracking." Journ of the Assoc. of Asphalt Paving Techn.. 2012, , 1909-1913.

[7.] Aurangzeb, Q.; Al-Qadi, I. Asphalt Pavements with High Reclaimed Asphalt Pavement Content: Economic and Environmental Perspectives. Transp. Res. Rec. 2014, 2456, 161169

[8.] Aurangzeb, Q.; Al-Qadi, I.L.; Ozer, H.; Yang, R. Hybrid life cycle assessment for asphalt mixtures with high RAP content. Resour. Conserv. Recycl. 2014, 83, 77-86.

[9.] Aurangzeb, Q.; Al-Qadi, I.L.; Ozer, H.; Yang, R. Hybrid life cycle assessment for asphalt mixtures with high RAP content. Resour. Conserv. Recycl. 2014, 83, 77-86.

[10.] Beeson, M., Prather, M., and Huber, G. A. Characterization of Reclaimed Asphalt Pavement in Indiana: Changing INDOT Specification for RAP." Transp. Research Board 90th Annual MeetingWashington, D.C. . (2011).
[11.] Bonaquist, R. Can I run more RAP?" HMAT: Hot Mix Asphalt Technology, 2007.12(5), 11-13.

[12.] Bongsuk Park A. Reclaimed Asphalt Pavement (RAP) Characterization to Maximize RAP Content in Polymer-Modified Asphalt Mixtures [Doctoral dissertation] (2020). 22-39.

[13.] Bowers, B.F.; Huang, B.; Shu, X.; Miller, B.C. Investigation of Reclaimed Asphalt Pavement Blending Efficiency through GPC and FTIR. Constr. Build. Mater. 2014, 50, 517-523.

[14.] Bowers, B.F.; Moore, J.; Huang, B.; Shu, X. Blending efficiency of Reclaimed Asphalt Pavement: An approach utilizing rheological properties and molecular weight distributions. Fuel 2014, 135, 63-68.

[15.] Chatti, K.; Zabaar, I. Estimating the E_ects of Pavement Condition on Vehicle Operating Costs; NCHRP Report 720; NCHRP: Washington, DC, USA, 2012.

[16.] Chen, J.S.; Huang, C.C.; Chu, P.Y.; Lin, K.Y. Engineering characterization of recycled asphalt concrete and aged bitumen mixed recycling agent. J. Mater. Sci. 2007, 42, 9867-9876.

[17.] Chinowsky, P.; Scheikert, A.E.; Strzepek, N.L.; Strzepek, K. Road Infrastructure and Climate Change in Vietnam. Sustainability 2015, 7, 5452-5470.

[18.] Christensen Jr, D., Pellinen, T., and Bonaquist, R. Hirsch Model for Estimating the Modulus of Asphalt Concrete." Journ of the Asso of Asphalt Paving Techn, 2003.72, 97-121.

[19.] Coleri, E.; Zhang, Y.; Wruck, B.M. Mechanistic-Empirical Simulations and Life-Cycle Cost Analysis to Determine the Cost and Performance Effectiveness of Asphalt Mixtures Containing Recycled Materials. Transp. Res. Rec. 2018, 2672, 143-154.

[20.] Copeland, A. Reclaimed Asphalt Pavement in Asphalt Mixtures: State of the Practice; Report FHWA-HRT-11-021; FHWA:Washington, DC, USA, 2011.

[21.] Copeland,A. ReclaimedAsphalt Pavement inAsphaltMixtures: State of the Practice (No. FHWA-HRT-11-021).

[22.] Daniel, J. S., and Mogawer, W. S. Determining the Effective PG Grade of Binder in RAP mixes." NETCR78, Project No. 04-4. 2010.

[23.] Del Ponte, K.; Natarajan, B.M.; Ahlman, A.P.; Baker, A.; Elliot, E.; Edil, T.B. Life-Cycle Benefits of Recycled Material in Highway Construction. Transp. Res. Rec. 2017, 2628, 1-11.

[24.] Del Ponte, K.; Natarajan, B.M.; Ahlman, A.P.; Baker, A.; Elliot, E.; Edil, T.B. Life-Cycle Benefits of Recycled Material in Highway Construction. Transp. Res. Rec. 2017, 2628, 1-11.

[25.] Doh, Y.S.; Amirkhanian, S.N.; Kim, K.W. Analysis of unbalanced binder oxidation level in recycled asphalt mixture using GPC. Constr. Build. Mater. 2008, 22, 1253-1260.

[26.] Druta, C.;Wang, L.; Zhu, T. Laboratory investigation of reclaimed asphalt pavement mixed with pure binder using X-ray CT scanner. In Proceedings of the Ninth International Conference of Chinese Transportation Professionals (ICCTP), Harbin, China, 5-9 August 2009; pp. 1-10.

[27.] Giani, M.I.; Dotelli, G.; Brandini, N.; Zampori, L. Comparative life cycle assessment of asphalt pavements using reclaimed asphalt, warm mix technology and cold in-place recycling. Resour. Conserv. Recycl. 2015, 104, 224-238.

[28.] Hainin, M.R.; Oluwasola, E.A.; Brown, R.E. Density Profile of Hot Mix Asphalt Layer during Compaction with Various Types of 
Rollers and Lift Thickness. Constr. Build. Mater. 2016, 121, 265277.

[29.] Huang, B., Shu, X., and Vukosavljevic, D. Laboratory Investigation of Cracking Resistance of Hot-Mix Asphalt Field Mixtures Containing Screened Reclaimed Asphalt Pavement." Jour of Mat in Civil Eng, 2011.23(11), 1535-1543.

[30.] Kim, S., Roque, R., Birgisson, B., and Guarin, A Porosity of the Dominant Aggregate Size Range to Evaluate Coarse Aggregate Structure of Asphalt Mixtures. Journ of Mat in Civil Eng, . 2009.21(1), 32-39.

[31.] Kriz, P.; Grant, D.L.; Veloza, B.A.; Gale, M.J.; Blahey, A.G.; Brownie, J.H.; Maccarrone, S. Blending and diffusion of reclaimed asphalt pavement and virgin asphalt binders. Road Mater. Pavement Des. 2014, 15,78-112.

[32.] Kvasnak, A., West, R., Michael, J., Loria, L., Hajj, E., and Tran, N. Bulk Specific Gravity of Reclaimed Asphalt Pavement Aggregate." Trans Res Rec Journ of the Trans Res Board, 2010. 2180, 30-35.

[33.] Lee, J.C.; Edil, T.B.; Tinjum, J.M.; Benson, C.H. Quantitative Assessment of Environmental and Economic Benefits of Recycled Materials in Highway Construction. Transp. Res. Rec. 2010, 2158, 138-142.

[34.] ] Li, X., Gibson, N., Andriescu, A., and S. Arnold, T. Performance Evaluation of REOB-Modified Asphalt Binders and Mixtures. Road Mat and Pav Design, 2017.18(sup1), 128-153.

[35.] Liu, M. H. Research and application prospect on cold recycling technology of asphalt pavement. App Mech and Mat. 2012. 204208, 1909-1913.

[36.] Ma, X., Leng, Z., Wang, L., \& Zhou, P. Effect of reclaimed asphalt pavement heating temperature on the Compactability of recycled hot mix asphalt. Materials, 2020. 13(16), 3621. https://doi.org/10.3390/ma13163621

[37.] McDaniel, R. S., Soleymani, H., Anderson, R. M., Turner, P., and Peterson, R. Recommended Use of Reclaimed Asphalt Pavement in the Superpave Mix Design Method." NCHRP Web Document 30, TRB, National Research Council, Washington, D.C. (2000).

[38.] Melillo, J.M.; Richmond, T.; Yohe, G.W. Climate Change Impacts in the United States: The Third National Climate Assessment; U.S. Global Change Research Program: Washington, DC, USA, 2014.

[39.] Mohammad, L.N.; Cooper, S.B.; Elseifi, M.A. Characterization ofHMAMixtures Containing High Reclaimed Asphalt Pavement Content with Crumb Rubber Additives. J. Mater. Civ. Eng. 2011, 23, 1560-1568.

[40.] Qiao, Y.; Dawson, A.R.; Parry, T.; Flintsch, G.W. Evaluating the e_ects of climate change on road maintenance intervention strategies and Life-Cycle Costs. Transp. Res. D Transp. Environ. 2015, 41, 492-503.

[41.] Qiao, Y., Dave, E., Parry, T., Valle, O., Mi, L., Ni, G., Yuan, Z., \& Zhu, Y. Life cycle costs analysis of reclaimed asphalt pavement (RAP) under future climate. Sustainability, 2019. 11(19), 5414. https://doi.org/10.3390/su11195414

[42.] Roque, R., Yan, Y., Cocconcelli, C., and Lopp, G. Perform an Investigation of the Effects of Increased Reclaimed Asphalt Pavement (RAP) Levels in Dense Graded Friction Courses." Final Report of Florida Department of Transportation, FDOT Contract No. BDU-77, University of Florida, Gainesville FL. . (2015).

[43.] Santos, J.; Bryce, J.; Flinsch, G.; Ferreira, A.; Diefenderfer, B. a life cycle assessment of in-place recycling and conventional pavement construction and maintenance practices. Struct. Infrastruct. Eng. 2015, 11, 1199-1217.

[44.] Shah, A.; McDaniel, R.; Huber, G.; Gallivan, V. Investigation of properties of plant-produced reclaimed asphalt pavement mixtures. Transp. Res. Rec. 2007, 1998, 103-111.

[45.] Sharma, B. K., Ma, J., Kunwar, B., Singhvi, P., Ozer, H., and Rajagopalan, N. Modeling the Performance Properties of RAS and RAP Blended Asphalt Mixes Using Chemical Compositional Information." Illinois Center for Transportation (ICT). Final Report of Federal Highway Administration, FHWA-ICT-17-001. 2017.

[46.] Shirodkar, P.; Mehta, Y.; Nolan, A.; Dubois, E.; Reger, D.; McCarthy, L. Development of blending chart for different degrees of blending of RAP binder and virgin binder. Resour. Conserv. Recycl. 2013, 73, 156-161.

[47.] Shu, X.; Huang, B.; Vukosavljevic, D. Laboratory evaluation of fatigue characteristics of recycled asphalt mixture. Constr. Build. Mater. 2008, 22, 1323-1330.

[48.] Silva, H.M.R.D.; Oliveira, J.R.M.; Jesus, C.M.G. Are totally recycled hot mix asphalts a sustainable alternative for road paving? Resour. Conserv. Recycl. 2012, 60, 38-48.

[49.] Singh, D., and Girimath, S. Influence of RAP Sources and Proportions on Fracture and Low Temperature Cracking Performance of Polymer Modified Binder." Construction and Building Materials, 2016. 120, 10-18.

[50.] Singh, D., and Sawant, D. Understanding Effects of RAP on Rheological Performance and Chemical Composition of SBS Modified Binder Using Series of Laboratory Tests." International Journal of Pavement Research and Technology, 2016. 9(3), 178189.

[51.] Sunarjono and N Hidayati 2019 IOP Conf. Ser.: Mater. Sci. Eng. 674012029

[52.] Trupia, L.; Parry, T.; Neves, L.; Lo Presti, D. Rolling resistance contribution to a road pavement life cycle carbon footprint analysis. Int. J. Life Cycle Assess. 2017, 22, 972.

[53.] Tiza, M. T., Mogbo, O. N., Duweni, E. C., \& Asawa, J. I. Recycled Asphalt Pavement: A Systematic Literature Review. Journal of Modern Technology and Engineering, 5(3). 2020,242-254

[54.] Underwood, B.S.; Guido, Z.; Gudipudi, P.; Feinberg, Y. Increased costs to US pavement infrastructure from future temperature rise. Nat. Clim. Chang. 2017, 7, 704-707.

[55.] Wang, F.; Wang, Z.; Li, C.; Xiao, Y.; Wu, S.; Pan, P. The Rejuvenating E_ect in Hot Asphalt Recycling by Mortar Transfer Ratio and Image Analysis. Materials 2017, 10, 574.

[56.] Wang, J.; Yuan, J.; Kim, K.W.; Xiao, F. Chemical, thermal and rheological characteristics of composite polymerized asphalts. Fuel 2018, 227, 289-299.

[57.] Wang, T.; Lee, I.-S.; Kendall, A.; Harvey, J.; Lee, E.-B.; Kim, C. Life cycle energy consumption and GHG emission from pavement rehabilitation with different rolling resistance. J. Clean. Prod. 2012, 33, 86-96.

[58.] Wang, Y. The effects of using reclaimed asphalt pavements (RAP) on the long-term performance of asphalt concrete overlays. Constr. Build. Mater. 2016, 120, 335-348.

[59.] West, R., Willis, J. R., and Marasteanu, M. Improved Mix Design, Evaluation, and Materials Management Practices for Hot Mix 
Asphalt with High Reclaimed Asphalt Pavement Content." National Cooperative Highway Research Program (NCHRP) Report 752, Project 09-46. 2013.

[60.] Wu, S.P.; Pang, L.; Mo, L.T.; Chen, Y.C.; Zhu, G.J. Influence of aging on the evolution of structure, morphology and rheology of base and SBS modified bitumen. Constr. Build. Mater. 2009, 23, 10051010.

[61.] Xiao, F.; Amirkhanian, S.N. Laboratory investigation of moisture damage in rubberised asphalt mixtures containing reclaimed asphalt pavement. Int. J. Pavement Eng. 2009, 10, 319-328

[62.] Xiao, F.; Amirkhanian, S.N.; Shen, J.; Putman, B. Influences of crumb rubber size and type on reclaimed asphalt pavement (rap) mixtures. Constr. Build. Mater. 2009, 23, 1028-1034.

[63.] Xiao, F.; Yao, S.; Wang, J.; Li, X.; Amirkhanian, S. A literature review on cold recycling technology of asphalt pavement. Constr. Build. Mater. 2018, 180, 579-604.

[64.] Xie, Z., Tran, N., Julian, G., Taylor, A., and Blackburn, L. D. Performance of Asphalt Mixtures with High Recycled Contents Using Rejuvenators and Warm-Mix Additive: Field and Lab Experiments." Journal of Materials in Civil Engineering, 2017. 29(10), 04017190.

[65.] Yang, R.; Ozer, H.; Kang, S.; Al-Qadi, I.L. Environmental Impacts of Producing Asphalt Mixtures with Varying Degrees of Recycled Asphalt Materials. In Proceedings of the International Symposium on Pavement LCA, Davis, CA, USA, 14-16 October 2014

[66.] Yang, R.; Ozer, H.; Kang, S.; Al-Qadi, I.L. Environmental Impacts of Producing Asphalt Mixtures with Varying Degrees of Recycled Asphalt Materials. In Proceedings of the International Symposium on Pavement LCA, Davis, CA, USA, 14-16 October 2014

[67.] Yang, Z.; Xu, W. Infrared Spectroscopy Analysis of the Blending of Virgin and RAP Binders in Hot Recycled Asphalt Mixture with CTBN as Tracer. J. Test. Eval.. in press.

[68.] Yang, Z.; Zhang, X.; Yu, J.; Xu, W. Effects of aging on the multiscale properties of SBS-modified asphalt. Arab. J. Sci. Eng. in press.2015.

[69.] Yang, Z.; Zhang, X.; Zhang, Z.; Zou, B.; Zhu, Z.; Lu, G.; Yu, H. Effect of Aging on Chemical and Rheological Properties of Bitumen. Polymers 2018, 10, 1345.

[70.] Yu, H.; Leng, Z.; Zhou, Z.; Shih, K.; Xiao, F.; Gao, Z. Optimization of preparation procedure of liquid warm mix additive modified asphalt rubber. J. Clean. Prod. 2017, 141, 336-345.
[71.] Zapata, C.E.; Andrei, D.; Witczak, M.W.; Houston, W.N. Incorporation of Environmental Effects in Pavement Design. Road Mater. Pavement Des. 2007, 8, 667-693.

[72.] Zaumanisa, B.; Mallicka, R.B. Review of very high-content reclaimed asphalt use in plant-produced pavements: State of the art. Int. J. Pavement Eng. 2015, 16, 39-55.

[73.] Zhao, S.; Bowers, B.; Huang, B.; Shu, X. Characterizing rheological properties of binder and blending efficiency of asphalt paving mixtures containing RAS through GPC. J. Mater. Civ. Eng. 2014, 26, 941-946.

[74.] Zhao, S.; Huang, B.; Shu, X. Investigation on Binder Homogeneity of RAP/RAS Mixtures through Staged Extraction. Constr. Build. Mater. 2015, 82, 184-191.

[75.] Zhao, S.; Huang, B.; Shu, X.;Woods, M.E. Quantitative evaluation of blending and diffusion in high RAP and RAS mixtures. Mater. Des. 2016, 89, 1161-1170.

[76.] Zhou, F.; Li, H.; Lee, R.; Scullion, T.; Claros, G. Recycled asphalt shingle binder characterization and blending with virgin binders. Transp. Res. Rec. 2013, 2370, 33-43.

[77.] Zhu, C. Evaluation of Thermal Oxidative Aging Effect on the Rheological Performance of Modified Asphalt Binders. Ph.D. Thesis, University of Nevada, Reno, NV, USA, 2015.

[78.] Zofka, A., Marasteanu, M., Li, X., Clyne, T., and McGraw, J Simple Method to Obtain Asphalt Binders Low Temperature Properties from Asphalt Mixtures Properties (With Discussion)." Journ of the Assoc of Asphalt Paving Techn, 2005 74, 225-282.

\section{How to Cite This Article}

Tiza, M.., Duweni, C., Mogbo, O., Terlumun S., and Asawa,J., Characterization of Reclaimed Asphalt Pavement and Optımızatıon in Polymer Modıfied Asphalt Blends: A Review, Civil Engineering Beyond Limits, 2 (2021), 27-34. https://doi.org/10.36937/cebel.2021.002.004 